\title{
Wetland Loss in Northeastern Italy Documented by Historical Maps
}

\author{
Silvia Elena Piovan ${ }^{\mathrm{a}}{ }^{*}$, Marco Filippini ${ }^{\mathrm{a}}$, Michael Edward Hodgson ${ }^{\mathrm{b}}$ \\ ${ }^{a}$ University of Padova - Department of Historical and Geographic Sciences and the Ancient World, silvia.piovan@unipd.it, \\ marco.filippini.883@gmail.com \\ ${ }^{b}$ University of South Carolina - Department of Geography, hodgsonm@sc.edu \\ * Corresponding author
}

Keywords: wetlands, historical maps, GIS, alluvial plain, ecosystem

Abstract:

Historical landscape and habitat reconstruction can be an important mitigation tool for regional habitat loss, conservation and restoration (NRC 1992; Swetnam et al. 1999; Steiner 2000). Among landscapes and habitats, wetlands play an important role in providing ecosystem services. Any loss of wetland areas may cause serious and sometimes irreparable environmental and habitat damages (Soule, 1991). Wetlands have a paramount importance for ecosystems and are protected by the Ramsar Convention and regulated and valorized, in different ways, by local and/or regional protection agency and laws.

Analysing trends of wetlands loss on a regional scale can now be performed using geo-historical approaches and remote sensing and GIS technologies. Many notable examples of wetlands loss studies using a combined geohistorical and GIS approach may be find in the literature. Much of the previous research on wetlands loss has focused on the United States where wetlands are more legally protected and regulated. Little research has focused on wetlands in southern Europe. The focus of this research is on wetland loss in the Southern Venetian-Po Plain (Northeastern Italy) through a comparison of contemporary and historical data with the analysis of remote sensing and historical maps. In particular, this work focuses on the province of Padova, well known for their abundance of inland wetlands in the past although greatly disrupted through drainage and agricultural expansion in the last century.

The Southern Venetian Po-Plain is an alluvial plain located between the Lagoon of Venice, the Po river and the Veneto pre-Alps piedmont region. This region is currently characterized by an apparent scarcity of wetlands in comparison to what is represented in many historical maps and described in historical documents. Some studies on wetlands in parts of the Venetian region have been conducted using different approaches. Typical research focused on single portions of larger wetlands or single ponds for the study of current biochemical conditions and ecosystems in the environment (e.g. Serandrei-Barbero et al., 2011; Pappalardo et al., 2016). Research on more extensive wetlands, land reclamations and humans-rivers relationships mostly focus on the analysis of the socio-economical conditions in the Po Delta and the Lagoon of Venice (e.g. Bertoncin, 2002; Novello, 2009). Despite numerous works on singular ponds or studies on larger water bodies in the Venetian area, there is still a poor knowledge of the amount, the extension and the type of wetlands in the Southern Venetian Po-Plain. A comprehensive survey of wetlands for the Venetian area has never been conducted, and the 'official' data are notably incomplete.

The objectives of this work were: 1) to perform a survey (Figure 1) of both historic and present-day wetlands in the province of Padova (northeastern Italy) using historical cartography (1882 map of the province of Padova by O. Morelli) and recent aerial orthophotos $(2015), 2)$ to provide a first estimation of the extraordinary loss of wetlands in this province due mostly to land reclamation processes of the last century, and 3) to discuss the prospects for further historical wetlands analysis based on additional historic maps $(1776,1801,1862,1882,1980)$ for a key area called Bassa Padovana (Padova's lowland). All quantitative analyses were performed through the use of a GIS. This research contributes to the discussion of small isolated wetlands (Figure 2) that have been created in the last century and their unique role in the ecosystems. 

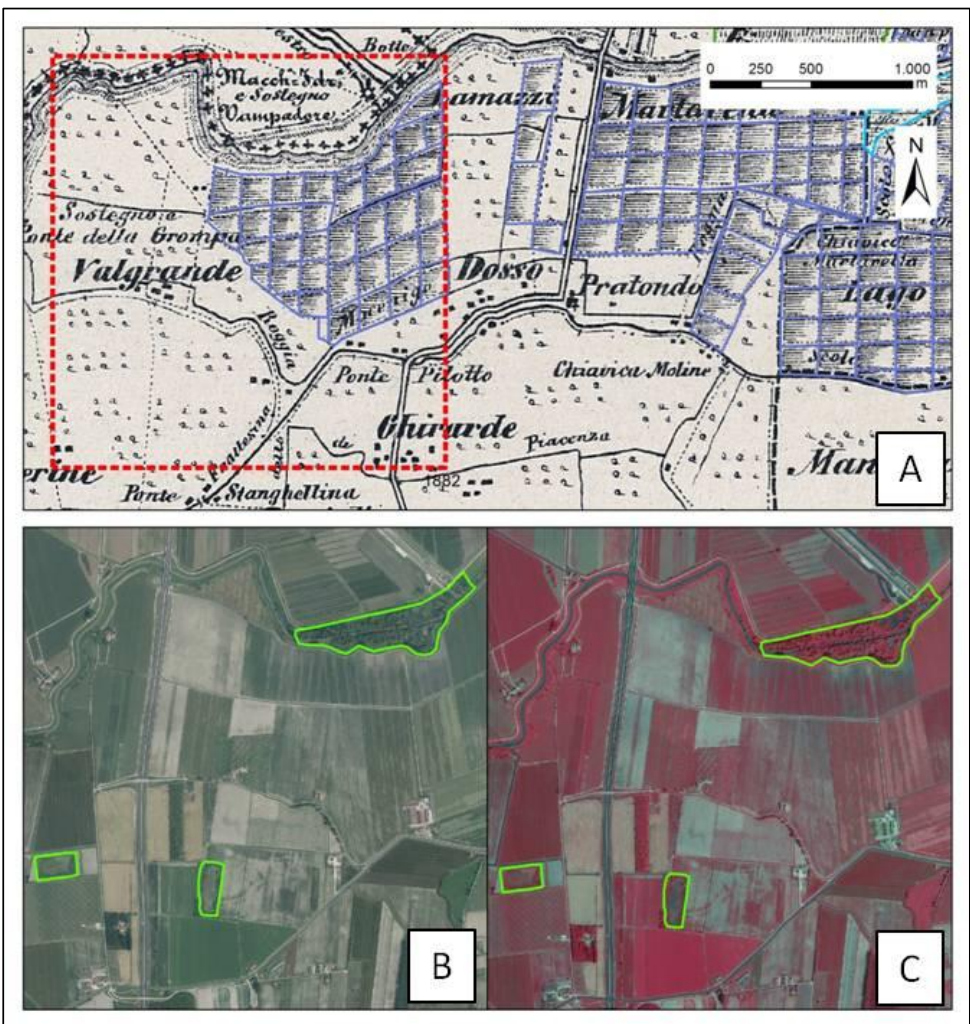

Figure 1. (A) Detail of the Valli Mocenighe area from the 1882 map by Orazio Morelli; (B) area in the red square as viewed in the natural color version of 2015 ortophotos and (C) in the color-IR version of the 2015 ortophotos. In blue and in green, the past wetlands and the 2015 wetlands are shown, respectively.

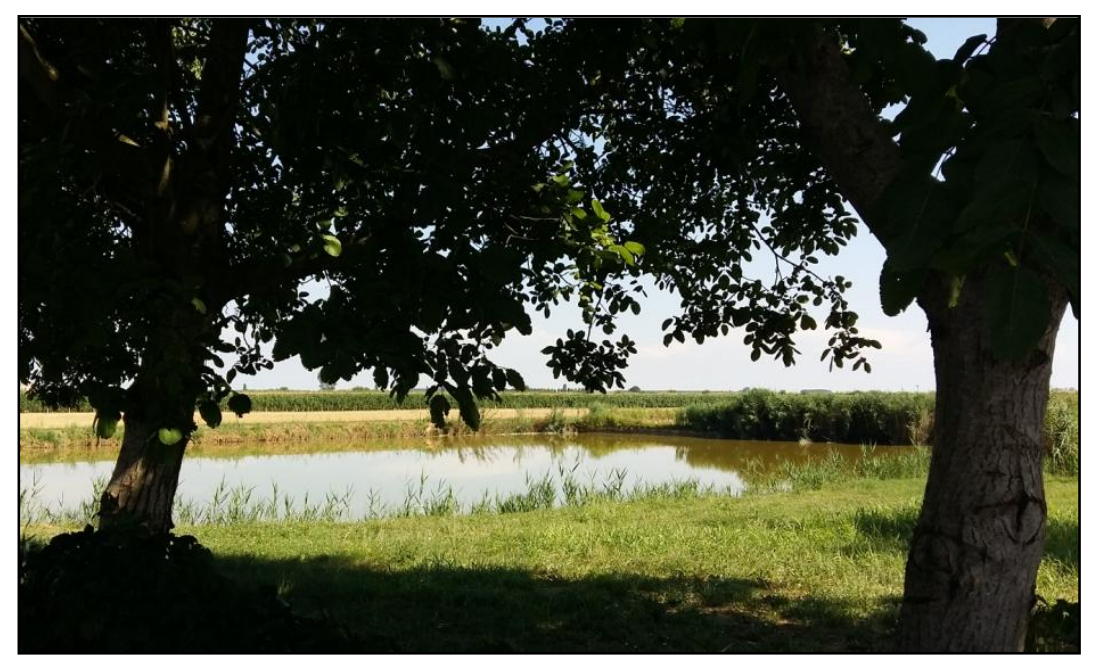

Figure 2. Former clay-pit transformed in the present time period in a geographically isolated pond (Bassa Padovana area). 